Res Publica. Revista de Historia de las Ideas Políticas ISSN: 1576-4184

http://dx.doi.org/10.5209/RPUB.60851

\title{
Danilo Kiš y la representación del totalitarismo
}

\author{
José Antonio Fernández López*
}

Recibido: 16 de febrero de 2018 / Aceptado: 15 de junio de 2018

Resumen. La obra de Danilo Kiš tiene como núcleo primordial el análisis de la existencia humana a merced de los totalitarismos. Sus libros se enfrentan a la violencia que lo abarca todo en el siglo XX, al mal metafísico que simbolizan Auschwitz y el Gulag. En el presente artículo daremos cuenta de cómo el autor despliega este propósito en su obra, conciliando historia, política y representación artística, el archivo y la ficción, mediante el desarrollo de una ética anamnética cuyos destinatarios son los seres humanos perdidos en la noche de la barbarie y el olvido.

Palabras clave: totalitarismo; historia; ficción literatura; ética anamnética.

\section{[en] Danilo Kiš and the Representation of Totalitarianism}

\begin{abstract}
The work of Danilo Kiš has as a primordial nucleus the analysis of human existence subjected to totalitarianism. His books are facing the violence that all-encompassing in the 20th century, the metaphysical evil symbolizing Auschwitz and the Gulag. In this article, we will account how the author unfolds this purpose in his work, reconciling history and artistic representation, archive and fiction, through the development of an Ethics of Remembrance whose recipients are the lost human beings in the Night of history, of barbarism and oblivion.
\end{abstract}

Keywords: Totalitarianism; History; Literary fiction; Anamnetic ethics.

Sumario: 1. Introducción. La literatura levanta acta de la violencia. 2. Del origen y la barbarie. Representar la Shoá. 2.1. La pulsión universalizadora de un "asunto familiar". 2.2. Reconstruir la Historia. 3. El tabú del Gulag y el arte de la novela. 3.1. Salvar del olvido al ser humano. 3.2. El principio de asimetría hermenéutica. 3.3. Coda: la meditación sobre la historia. 4. Conclusión: el espejo invertido del mundo.

Cómo citar: Fernández López, J.A. (2018). Danilo Kiš y la representación del totalitarismo, en Res publica 21.2, 289-303.

\footnotetext{
* Universidad de Murcia

joseantonio.fernandez13@um.es
} 


\section{Introducción. La literatura levanta acta de la violencia}

Concentrarse con energía en el horror de la existencia en la tierra, en la imperfección del mundo, en las miríadas de vidas truncadas, en las fieras que se matan entre ellas, en la serpiente que pica al cervatillo que duerme en la sombra, en lobos que degüellan corderos.

Danilo Kiš, La Enciclopedia de los muertos.

La obra del escritor yugoslavo Danilo Kiš (Subotica, 1935-París, 1989) destaca por la originalidad de su carácter, por su gran capacidad de innovación literaria y por una profunda reflexión filosófico-política sobre la historia, la cultura y la condición del ser humano. Expresión de la existencia humana a merced de la violencia política, los libros de Kiš se enfrentan a la densidad de un mal metafísico que lo abarca todo en el siglo XX. Testimonio del totalitarismo y de la intransigencia ideológica, de los desvaríos políticos y los delirios nacionales, su narrativa, estimulada por una personal ironía, realiza una reconstrucción de la historia desde una memoria que es compasiva y creativa a la vez. Convencido de que la literatura en este siglo no podía ser más que la descripción y la condena de la injusticia, concebirá la tarea de escribir como el incansable esfuerzo por levantar acta de la barbarie de nuestra época. Frente a la cosificación de los seres humanos, sus libros representan un memento pormenorizado, exhaustivo, con la visibilidad litúrgica de una letanía, de unos personajes que simbolizan a todas las vidas truncadas por la violencia. Desde sus inicios en $\mathrm{La}$ buhardilla, pasando por Una tumba para Boris Davidovich y culminando en los relatos de la Enciclopedia de los muertos, escribir significará para Danilo Kiš salvar y preservar aquello que está a punto de desaparecer; salvar del olvido lo individual; empresa intelectual de un moralista beligerante frente a cualquier intento de anular la singularidad anónima de las víctimas de la Historia en el siglo XX. Traducida toda su producción novelística al español, este esfuerzo, sin embargo, no ha suscitado aún una crítica literaria consistente de la misma, como tampoco una reflexión filosófica en torno a la singular aproximación kisheana al fenómeno del totalitarismo político y a sus implicaciones éticas y metafísicas.

\section{Del origen y la barbarie. Representar la Shoá}

Comenzado veinte años después de la publicación de los grandes testimonios del Holocausto, el ciclo narrativo kisheano sobre la Shoá hubo de enfrentarse en su gestación y desarrollo a un doble reto: la transposición de unas experiencias personales que se remontaban a la niñez y la inmersión en una temática literaria donde los límites entre la autenticidad y la banalidad representativa resultan harto difusos. ¿Cómo narrar la Shoá después de Primo Levi, Elie Wiesel, David Rousset o Robert Antelme? ¿Cómo dotar de autenticidad a un relato inspirado en la traumática experiencia de un niño, escrito más de dos décadas después de aquella infancia? Kiš responde apoyándose en la tradición literaria más moderna, en una concepción estética inspirada en los formalistas rusos donde la amplificación de la forma le permite adentrarse en un núcleo de experiencias traumáticas, sin incurrir en ex- 
$\operatorname{cesos}^{1}$. Este tratamiento formal de la experiencia, que podría desembocar en una imagen excesivamente distante de los hechos, tiene como contrapunto su elevado lirismo. Singularidad de la prosa kisheana, su marcado carácter poético le confiere una autenticidad que, exenta de todo patetismo, permite un posicionamiento eficaz para dar cuenta del objeto de una obsesión: el exterminio de una familia de judíos húngaros, los Kohn/Kiš y la supervivencia del hijo de uno de ellos, Danilo. La misteriosa desaparición de personas, encarnada en su familia, y que, confiesa el autor, constituye el núcleo de su literatura, es para él uno de los fenómenos políticos cruciales del siglo $\mathrm{XX}^{2}$.

Psalam 44 ("Salmo 44"), la segunda novela de Danilo Kiš, fue publicada en 1962 por la editorial belgradense Kosmos, en un volumen doble que incluía también Mansarda ("La buhardilla") ${ }^{3}$. Con ella inicia el autor el ciclo narrativo sobre la Shoá. En Salmo 44, ficción del Holocausto en la Voivodina y en los campos de exterminio polacos, convergen lo histórico, lo autobiográfico y lo estilísticamente posmoderno. Más allá de la crónica concentracionaria al uso y mucho más atrevida que la ficción novelística sobre la cuestión que vendría después, esta obra pone la poética del joven Kiš al servicio de una muy particular ética anamnética: la imaginación compasiva con las víctimas de la barbarie. Y es ahí, no obstante, donde descansa "la debilidad" llamativa de la obra, su carácter de "tentativa juvenil", de obra no consumada. Débil no por cierto patetismo que la caracteriza o por su énfasis en una forma sostenida de intriga, sino por la "ausencia fatal", confiesa el autor, de una mínima distancia irónica desde la que abordar un tema de tales características ${ }^{4}$, distancia esta que, sin embargo, pasará a convertirse en sello distintivo de la narrativa kisheana. En cualquier caso, a pesar de sus limitaciones Salmo 44 posee, también, una función bien precisa y relevante como testimonio de un proceso de búsqueda y de maduración, y es la de ser ensayo del característico procedimiento de reconstrucción histórica y documental de la ficción kisheana: la trasposición de las experiencias personales y la "reconstrucción documental" de la realidad".

\subsection{La pulsión universalizadora de un "asunto familiar"}

Frente al caos del mundo y el ímpetu de sus fuerzas arrolladoras, la palabra, la escritura, es la única creación posible. En palabras de Georges Steiner, "no nos quedan más principios". Danilo Kiš concibe el caos cósmico, a merced de cuya violencia se halla el ser humano, como el paso previo a toda literatura. Y la literatura surge, en su caso, de la necesidad de explicar el porqué de esta cólera divina, la esencia teológico-política de una furia genocida, encarnada en una historia furiosa, que convirtió a los suyos y a él mismo en víctimas. Fenomenológicamente, esta literatura no aspira a reconstruir mundos pretéritos ya clausurados. El nuevo mundo de relaciones que

1 A. Prstojević, "La Shoah et le témoinage littéraire", en Ch. Kègle, Les recits de survivance, Québec, PUL, 2007, p. 91. El mismo autor reconoce sin ambages esta dependencia: D. Kiš, Le résidu amer de l'expérience: entretiens, Paris, Fayard, 1995, p. 25.

Ibidem, p. 196.

D. Kiš, Mansarda-Psalam 44, Beograd, Kosmos, 1962.

D. Kiš, Le résidu amer, op. cit., pp. 121.

Ibidem, p. 199. Cf. B. Gorjup, "Textualizing the Past: The Function of memory and History in Kiš’s Fiction", Review of Contemporary Fiction 14, 1 (1994), pp. 161-168.

6 G. Steiner, Gramáticas de la creación, Madrid, Siruela, 2001, p. 11. 
urde cambia la esencia de las cosas mismas, creando no solo nuevas imágenes, sino nuevos fenómenos del mundo de la vida. Recrear el mundo es, visto desde la perspectiva kisheana, hacer que los lugares, las personas y los hechos "se transformen de nuevo en magma como antes de la creación"7.

A pesar de su rechazo a ser presentado como "un autor judío", Danilo Kiš es un escritor asociado personal, ética y estéticamente a la Shoá ${ }^{8}$ Y no de una manera cualquiera, circunstancial o anecdótica. Escribe sobre el Holocausto con tal fuerza y originalidad que su obra representa, sin lugar a dudas, un auténtico novum estético en la representación artística de esta catástrofe. La elaborada inmersión en la Shoá que representa Circo familiar se despliega en forma de tríptico, en tres volúmenes diferentes que cubren aproximadamente una década de la vida de Danilo Kiš y que significan su maduración como escritor. Rani jadi: za decu i osetljive ("Penas precoces: para niños y personas sensibles") $)^{9}$, publicado en Yugoslavia en 1970, es una colección de relatos que contiene breves bosquejos de su vida en el suroeste de Hungría durante la II Guerra Mundial. El segundo libro en términos de contenido fue, sin embargo, el primero de los tres en ser escrito: Bašta, pepeo ("Jardín, ceniza"), publicado en $1965^{10}$. Esta magnífica novela explora la historia del padre desaparecido, desde la perspectiva de la viva y dúctil conciencia de un niño, metamorfoseado, merced a la narración, en adulto. La novela da voz a los ecos de una infancia cuya naturaleza queda marcada para siempre por la pérdida del progenitor. La desaparición del padre, una suerte de contra-profeta mesiánico, se convierte en símbolo de la desaparición del mundo de los judíos de Europa Central. Cerrando el ciclo se encuentra Peščanik ("El reloj de arena", 1972)11, sin lugar a dudas, la obra magna que simboliza y cierra la primera época de la novelística kisheana. En ella somos testigos del principio del fin del padre desde una perspectiva polifónica. Kiš convierte su prosa en una herramienta excepcionalmente afinada en el plano formal. Con su elabora urdimbre, dota de moralidad a un mundo crepuscular traspasado por la violencia, la segregación política y la injusticia, levantado testimonio de una de sus víctimas.

Es mérito de la obra y de la competencia narrativa de Kiš el tratamiento que Jardín, ceniza da al Holocausto y el tipo de representación que de esta aproximación al objeto resulta. Con este fin, ensaya en la novela dos de los procedimientos literarios que se convertirán en sello indiscutible de su poética: la enumeración y la cita. Una amplificación de la forma tendente a propiciar el peso de la autenticidad frente al realismo de los hechos desnudos y la parquedad de la acción. La ausencia de intencionalidad moral en el plano externo del relato, de reflexiones apodícticas y de representaciones cargadas de patetismo y, sobre todo, el modo logrado de expresión formal de las percepciones de un niño, hacen del libro un caso excepcional en el tratamiento literario de la Shoá. Kiš consigue superar la "dificultad relacional" del objeto representado y la representación misma, dándole forma a ese singular espacio, indeterminado, entre la subjetividad de las vivencias y la posibilidad de su expresión ${ }^{12}$. Como un funambulista sobre el vacío, el escritor transgrede y represen-

\footnotetext{
D. Kiš, Le résidu amer, op. cit., p. 75.

N. Czarny, "Imaginary-Real Lives: On Danilo Kiš”, Cross Currents 3 (1984), pp. 282-283.

D. Kiš, Rani jadi: za djecu i osjetljive, Beograd, Nolit, 1970. Como referencia de la traducción al castellano: D. Kiš, Circo familiar (Penas precoces; Jardín, ceniza; El reloj de arena), Barcelona, Acantilado, 2007.

D. Kiš, Bašta, pepeo, Beograd, Prosveta, 1965.

D. Kiš, Peščanik, Beograd, Prosveta, 1972.

Referencias fundamentales sobre este asunto, desde un extremo al otro de la factibilidad de la representación
} 
ta, con fortuna, en los límites de lo indecible, aportando al lector "un conocimiento íntimo del mal que nunca abuse de sus sentimientos"13.

Emparentada con Jardín, ceniza, tanto en la temática como en la excepcionalidad de su resolución estilística, se encuentra la novela Sin destino (1975), del escritor húngaro Imre Kertész (1929-2016), superviviente de los campos de concentración de Auschwitz y Buchenwald ${ }^{14}$. Kertész plantea en Sin destino, cínica y desgarradamente, la posibilidad de la existencia de formas aberrantes de felicidad. Por encima de las marcadas diferencias entre sus respectivas narrativas, la lectura comparada de Jardín, ceniza y Sin destino pone de relieve la existencia de una más que notable comunión estética entre ambas ${ }^{15}$. Esta se encuentra, sin duda, en el evidente uso de la distancia irónica en la aproximación literaria a la Shoá que realizan. En el caso de Danilo Kiš, focalizar la atención simplemente en la exuberante modernidad técnica de su literatura impide reconocer la raíz de esta "diferencia". Su estética es indisociable de las respuestas ontológicas que aporta a las aporías del lenguaje y de la verdad, de la historia y de sus protagonistas. A través de ella habla y se recrea la memoria. "Proceso de galvanoplastia", "fuente de meditaciones melancólicas", respuesta a la "doble duda del conocimiento" ", la memoria es el nutriente de la ficción, un caldo primigenio en el que los límites del tiempo son forzados.

La naturaleza ético-política de esta empresa tiene como contrapunto una disposición de ánimo estético que busca suprimir todo asomo de tragedia, de banalización, toda tentación de una representación que se acerque mínimamente al kitsch. En Penas precoces, el cortafuego frente a la banalidad viene de mano de una ironía refinada y sostenida, que, íntimamente unida al conocimiento de aquello sobre lo que se despliega, señala la distancia frente a cualquier tentación banal y despierta en el lector la sensación de autenticidad ${ }^{17}$. Gracias a ella, a lo largo de toda la obra puede percibirse una sensibilidad entrelíneas, fijada a las palabras, una poética que exprime toda su impronta en el fragmento y que es incapaz de cualquier exceso verbal, vinculada a la expresión de "momentos privilegiados"18.

\subsection{Reconstruir la Historia}

Pocos son los objetos que sobreviven a la voracidad inmisericorde del tiempo. Fragmentos, documentos, fotografías, retazos de vidas, que pocas veces han contado en la verdadera historia universal de la infamia con una voz que las preserve del vacío. La carta de Eduard Sam -trasunto de Eduard Kiš, padre del autor- a su hermana

de la Shoá: S. Friedlander, Probing the Limits of Representation, Cambrigde, HUP, 1992; B. Lang, Holocaust Representation. Art within the Limits of History and Ethics, Baltimore, John's Hopkins UP, 2000. D. Lacapra, Representar el Holocausto: Historia, teoria y trauma, B. Aires: Prometeo, 2007; H. White, The Content of the Form: Narrative Discourse and Historical representation, Baltimore, John's Hopkins UP, 1987.

13 A. Prstojević, "La Shoah et le témoinage littéraire”, en Kègle (ed.), op. cit., 2007, p. 90.

14 I. Kertész, Sin destino, Barcelona, Acantilado, 2001.

15 Calificar Sin destino de "secuela" de Jardín, ceniza, tal como insinúa Mark Thompson es una apreciación errónea. Obvia el sentido de ambos relatos amén de la intrahistoria de la novela de Kertész, desde que el escritor húngaro la iniciara (1960) hasta que consiguió, casi una década después, que una editorial se atreviera a publicarla. Cf. M. Thompson, Birth Certificate. The Story of Danilo Kiš, Ithaca, Cornell U. P., 2013, p. 91.

16 D. Kiš, Jardín, ceniza, op. cit., pp. 156-157.

17 D. Kiš, Le résidu amer, op. cit., pp. 82-86.

$18 \quad$ Ibidem, p. 240. 
Olga, situada al final de El reloj de arena, es el eje sobre el que vertebra la estructura de la obra y, en última instancia su sentido profundo como creación artística. En la arquitectura genial que exhibe el diseño de la obra, este texto auténtico es esa clase de cimentación realizada sobre roca viva ${ }^{19}$. La carta es la tabla de materias de la novela. Las palabras auténticas y reales del padre, preservadas por la materialidad de esa misiva, trascienden el tiempo y actualizan y desvelan el significado de todo la que la obra ha ido apuntando fragmentariamente en su desarrollo. Tienen, pues razón, los que califican este documento singular como el lienzo, la materia primigenia y la esencia de Pě̌čanik ${ }^{20}$. Una tarea se le impone al creador de ficciones desde el archivo familiar: descifrarlo todo, sustentarlo todo en pruebas intelectuales y no sólo en experiencias líricas, descifrar como un exegeta el sentido de cada palabra, de cada fenómeno aludido, "recrear la flora y la fauna de la época de esta carta"21. Novela, pues, arqueológica, El reloj de arena es la reconstrucción de los fragmentos de una vida, presentados en forma de mosaico. Auto sacramental, es también una suerte de políptico de la pasión del padre y, por extensión de la pasión de los millones de seres humanos que desaparecieron entre el humo y la niebla de los campos ${ }^{22}$.

En El reloj de arena los documentos cobran vida, convirtiendo la ficción en realidad verdadera. El efecto resultante es el de una suerte de historización de la novela. La inserción documental saca a la luz los hechos sobre los que se asienta la historia, convertidos en "indicadores de historicidad" 23 . La novela cobra vida y autenticidad en la tensión existente entre la experiencia limitada del personaje protagonista y la utilización de informes, documentos, referencias o citas, esto es, retazos, huellas, indicios que el lector halla jalonando el camino del padre. La novela transforma así la historia en búsqueda y salvaguardia de las huellas escritas. La propensión kisheana a la catalogación de personas, objetos e ideas, que alcanzará su clímax en Enciklopedija mrtvih, tiene uno de sus precedentes fundamentales en las páginas de Peščanik ${ }^{24}$. En medio de diálogos y descripciones, de evocaciones desvariadas y densas experiencias oníricas, el listado de los judíos exterminados de Novi Sad se erige como la verdadera razón de ser moral del libro: frente a la cosificación de los seres humanos, el memento pormenorizado, exhaustivo, con la visibilidad litúrgica de una letanía, supone la actualización de sus vidas malhadadas, su recuperación moral para una historia que siempre tiende a olvidarlos ${ }^{25}$.

El determinismo de la historia y la futilidad de cualquier aspiración de libertad, la inexistencia de lo azaroso como fenómeno objetivo, son una condena para la singularidad humana. Solo lo singular es humano, frente a la inhumanidad de una totalidad que devora al individuo. "Sólo lo aislado puede morir, y todo lo mortal está solo", afirma Franz Rosenzweig en La estrella de la redención ${ }^{26}$. La vida literaria de Eduard Sam,

19 Kiš ya había contado previamente la historia de esta misiva, en concreto en una entrevista de 1973 concedida a Milivoje Pavlović, para la revista belgradense NIN ("Pisanje kao terapija", NIN 1156 (1973), p. 44). En 1987 Kiš permitió a la redacción de la revista croata Gradac su reproducción. Cf. M. Thompson, op. cit., p. 141; M. D. Birnbaum, "History and Human Relationships in the Fiction of Danilo Kiš", Cross Currents 8 (1989), p. 348.

20 A. Prstojević, Le roman face à l'Histoire, Paris, L'Harmattan, 2005, p. 252.

21 D. Kiš, Le résidu amer, op. cit., p. 31.

22 Ibidem, p. 30.

23 J-P. Morel, Préface à A. Prstojević, Le roman face, op. cit., p. VII.

24 Cf. M. Rizzante, "De l'idéal encyclopédique", L'Atelier du roman 8 (1996), pp. 42-51.

25 D. Kiš, El reloj de arena, op. cit., pp. 375-380.

26 F. Rosenzweig, La estrella de la redención, Salamanca, Sígueme, 1997, p. 44. 
que es una revuelta frente al hecho insoportable de la propia vida, simboliza también una rebelión frente a la historia, frente al destino inmisericorde que ha sentenciado ya su muerte, eliminando su substancia al convertirla en una condena. El escritor, testigo y víctima de la desaparición de su vida, emprende una tarea de misericordia, pero, también, de justicia histórica: recrear y salvar la vida malograda del hombre que encarna su padre. Es por ello, que la ficción se torna espejo del mundo ${ }^{27}$. La vida de Eduard Kiš, por mor del espíritu de la narración, renace al sentido en la vida de E.S. En la voluntad por desarrollar una comprensión ética y poética del pasado, emerge la fuerza capaz de reconstruir mediante la ficción el mundo de la vida destruido por la historia. Recrear el mundo para corregir el curso de la historia es, desde luego, una forma de afanarse en el fracaso. Sin embargo, aunque es una revuelta imposible, posee una eficaz virtualidad: recuperar para el conocimiento y la significación la existencia de aquellos que, despojados primero de toda consideración ético-política, transformados en parias ${ }^{28}$, fueron abandonados después por la justicia de Dios. Frente a la indiferencia de la historia el don de la concreción y de la veracidad. La técnica documental, el elogio del fragmento, convierten los retazos, las citas, los registros y las fotografías en objetos impregnados de la esencia de seres humanos concretos. La literatura recrea la historia, atestigua su veracidad. La fuerza de un testimonio, de un documento, de una carta, su nuda humanidad, expresa, en sus palabras y en sus silencios, en lo decible que muestra y en lo indecible que apunta, los límites de toda ficción y de toda realidad.

\section{El tabú del Gulag y el arte de la novela}

En la Yugoslavia de finales de los años setenta del siglo pasado un affaire literario traspasó los límites de lo artístico y de su representación, llegando a convertirse en un asunto público, en un escándalo de insospechadas y llamativas consecuencias. Čas anatomije ("Lección de anatomía", 197729) es la historia de la campaña de acoso y difamación desplegada contra Danilo Kiš, contada por él mismo; también es la réplica, virulenta y apasionada, de un escritor a aquellos que le acusaron y mancharon su nombre. Libro singular, más allá del ensayo y del martirologio, y, por encima de todo y de todos, es una apología del arte moderno, un tratado estético que levanta acta de la recuperación, por parte de un escritor, de su espacio literario propio frente a los prejuicios y al poder político establecido. Cargado de intuiciones proféticas tristemente cumplidas, el libro, inspirado por la Dijalektički antibarbarus de Miroslav Krleža ${ }^{30}$, será asimismo una crítica airada contra la corrupción intelectual y moral de las élites culturales.

\footnotetext{
Cf. L. Proguidis, "Danilo Kiš, portrait de familia”, L'Atelier du roman 8 (1996), pp. 79-90.
}

28 Eduard Kiš, el padre de Danilo encarna sin lugar la figura del judio paria teorizada por Hannah Arendt. En La tradición oculta, Arendt ha destacado cómo esta imagen ha permanecido asociada a la identidad judía europea desde el inicio del proceso de asimilación. Todos los judíos europeos, asimilados o no, compartieron, más allá de la llegada de las leyes raciales y la implantación del dominio alemán en prácticamente toda Europa, esta condición de paria. En el París de los años treinta, después de haber huido de Alemania convirtiéndose en una Heimatlosin, Arendt se topa con la obra de Bernard Lazare, a quien el affaire Dreyfus le descubrió la inequívoca cualidad de paria como específica de la existencia del pueblo judío. Cf. H. Arendt, La tradición oculta, Barcelona, Paidós, 2004, pp. 58-61.

29 D. Kiš, Čas anatomije, Beograd, Arhipelag, 2012; Lección de anatomía, Barcelona, Acantilado, 2013.

30 M. Krleža, Dijalektički antibarbarus, Sarajevo, Oslobođenje, 1983. 


\subsection{Salvar del olvido al ser humano}

Lección de anatomía es la réplica a una campaña de desprestigio basada en la más grave acusación que puede lanzarse contra un escritor, la de plagio, y en la que el corpus delicti era una novela: Grobnica za Borisa Davidoviča ${ }^{31}$. Una tumba para Boris Davidovich, cuyo subtítulo reza "Siete capítulos de una misma historia", es una colección de relatos autónomos cuyo nexo común es el hecho y el modo de aproximación a dicha "historia". Seis de los relatos nos acercan, a partir del uso de documentos reales, apócrifos o resultado de la invención, al trágico universo de las purgas estalinistas y de la destrucción del Komintern. La primera de las historias, "La navaja con la empuñadura de palo de rosa", a modo de pórtico, ofrece una reflexión sobre la moralidad y los propósitos personales inherentes a la actividad revolucionaria. Tal vez, por esta razón, quedó al margen de la batalla que estaba por venir ${ }^{32}$. Emparentado espiritualmente con el resto, el séptimo relato es la traducción de la crónica de un proceso inquisitorial del siglo XIV contra un judío converso, acompañada de bibliografía y de una nota del autor. La compenetración de ficción y realidad, la sutil fusión del archivo dentro de la narración, se despliegan en una empresa que aspira a que el lector empatice con unos personajes arrollados por la historia, pudiendo así reconstruirla moralmente. Obra literaria excepcional a la vez que desazonadora, Una tumba es "una desviación". No reverencia al "Hombre", ni a "la Idea", ni a la "Tradición", ni a ninguna clase de "patria" ${ }^{33}$. Alegato contra la barbarie, muestra simple y llanamente la destrucción del ser humano por el totalitarismo.

La maestría borgiana para utilizar los más diversos materiales documentales, trocándolos cuando es preciso, y que es reconocible también en Isaak Babel o en Edgar Allan Poe, inspira la novelística de Una tumba para Boris Davidovich. "Usar y trucar" es un procedimiento documentalista que tiene en Borges la impronta de una indagación filosófica. Propicia una literatura que se enfrenta al hombre, desde planos distintos (tiempo, espacio, destino), e intenta comprender la metafísica de la condición huma$\mathrm{na}^{34}$. Kiš, que reconoce sin ambages su dependencia formal del procedimiento, afirma, sin embargo, la profunda diferencia entre el uso del mismo en su literatura y en la de Borges, una diferencia basada en el valor de la historicidad y en la dimensión ético-política de sus protagonistas: "El hombre de Borges es un yogui, los personajes de Una tumba para B. D. son comisarios (por utilizar la dicotomía de Koestler)"35. Al montaje de los hechos y a la manipulación de la realidad de la historia soviética oficial, Kiš opone una manipulación creativa y literaria, cuyo propósito es, sin embargo, revelar la verdad histórica y objetiva ${ }^{36}$. Los documentos sirven para descubrir esa historicidad, ampliando, densificando, dotando de substancia, la experiencia humana.

31 D. Kiš, Grobnica za Borisa Davidoviča, Beograd, Arhipelag, 2011; Una tumba para Boris Davidovich. Barcelona, Acantilado, 2006.

32 S. Shishkoff, "Košava in a Coffe Pot or a Dissection of a Literary Cause Célèbre", Cross Currents 6, 1987, p. 341.

33 D. Kiš, Le résidu amer, op. cit., p. 142.

34 "Tlon, Uqbar, Orbis Tertis" (1940) es, en este sentido, una de las primeras reflexiones de la literatura moderna sobre una obra que transforma la realidad, gracias a la narración en primera persona y a la capacidad de intercambio de datos contradictorios proporcionados por el autor: J. L. Borges, "Tlön, Uqbar, Orbis Tertis", en Ficciones, O. C. II, Barcelona, Círculo Lectores, 1995, pp. 19-31.

35 D. Kiš, Lección de anatomía, op. cit. p. 56.

36 Ch. Salmon, Tumba de la ficción, Barcelona, Anagrama, 2001, p. 24. 
A despecho de este compromiso con la Historia, Kiš confiesa hallar una suerte de "inspiración invertida" en la obra de apolítica de un singular miembro del exilio ruso. Contrapunto imprescindible de su propio arte, en Vladimir Nabokov el autor yugoslavo reconoce un predominio de lo estético frente a lo moral que no puede ni debe desdeñarse. Todo artista necesita como referencia, para substraerse del porvenir de cualquier ilusión transcendental, una distancia mínima con respecto a la nuda materialidad de los hechos. Antídoto frente a veleidades morales o juicios maximalistas, Nabokov es el ejemplo del artista que cultiva su "propio jardín" frente a las ideologías. Ni fue Solzhenitsyn antes de Solzhenitsyn, ni escribió sobre los bolcheviques con odio, ni quiso ser un testigo magistral como Babel o Pilniak, ni ser Koestler antes que él, porque prefirió situar su apuesta fuera del momento histórico. Como un Demiurgo platónico conjeturó que el mundo de los hechos es mera apariencia, mientras que la representación artística pertenece al mundo eidético de los arquetipos ${ }^{37}$. En sus obras, Nabokov desprecia al animal político porque carece de idealismo: su mundo es tan vacío y simplificado que no puede ser objeto de arte, mas cuando se apresta a soñar, lo mejor es guardar silencio. La barbarie solo puede ser combatida desde el arte. Antídoto contra la locura del arte convertido en panfleto, Nabokov reivindica el sueño, el juego del espíritu, la imaginación. Un arte que prueba, en la claridad del instante, la posibilidad de la existencia del paraíso en un mundo sin Dios.

El halo nabokoviano reconforta al espíritu con las flores volantes de sus mundos. Sin embargo, para Kiš, aclarada la conciencia desde la distancia, en la intemperie sigue acechando el caos, el ruido, el eco de los paisajes grises y crueles de la Kolymá del infortunado Varlam Shalamov. Por ello, al margen de matices diferenciales o de concomitancias, la poética de Kiš es incomprensible si se obvia su decidido esfuerzo por desencadenar una renovada mirada a la historia. En este sentido, los relatos que se incluyen en Una tumba para Boris Davidovich pueden ser contemplados como los capítulos de una novela de formación invertida, inspirada en la negatividad del mundo. Historias ejemplares de años de aprendizaje nada ejemplares, en las que lo metaliterario y lo biográfico se entretejen en un tapiz con el que el artesano consigue insuflar a sus palabras la categoría epistemológica de "verdad", transubstanciando los materiales de la ficción en realidad, haciendo del pasado frío y anónimo un presente insuflado por la tragedia del espíritu humano.

Paradojas del arte y de la ética, el narrador que crea ficciones está comprometido con el desvelamiento de la verdad histórica. Utilizando, si se nos permite, una imagen arriesgada, el espiritu de la narración, que en Thomas Mann hace sonar las campanas de Roma, fuerza el sentido de la mirada del angelus novus de Benjamin. Transformando el gran relato en microhistoria, el archivero que urde ficciones no recrea los grandes imperios perdidos ni las culturas sepultas, no ejerce de autor de best sellers históricos. Más allá de la empresa del cronista, condicionada por la inmediatez, el creador de ficciones ejerce de arqueólogo. No es extraño, pues, que el compromiso artístico iniciado en Una tumba, culminara en los relatos de la Enciclopedia de los muertos, historias "de escribanías, de las tumbas vacías", la biografía como cenotafio $^{38}$. Salvar del olvido lo individual es la empresa intelectual de un moralista que se resiste a que el discurso de la totalidad anule la singularidad anónima de las

D. Kiš, Homo Poeticus: Essays and Interviews, NY, Farrar, Strauss \& Giroux, 1995, p. 151.

38 Cf. C. Coquio, "La biographie comme cénotaphe", en V. Deshoullières, Les Pierres de l'offrande, Zürich, Akanthus, 2003. D. Kiš, Enciklopedija mrtvih, Beograd, Arhipelag, 2011; La Enciclopedia de los muertos, 
víctimas, y para ese fin, una literatura que insista en lo particular, en la desemejanza, en la "diferencia sagrada" de cada ser humano.

La tarea del escritor en un mundo desquiciado es una empresa envuelta por un halo fantástico. Pero dado que la forma contemporánea de lo fantástico es la erudición, una nueva poética se abre paso en la escena de la aldea global. El tiempo de las "invenciones y fantasías" ya caducó en lo literario, según Kiš ${ }^{39}$. La multiplicidad de la extrañeza del mundo moderno ha permitido ver cumplirse la intuición precursora de Dostoievski, según la cual nada es más fantástico que la realidad ${ }^{40}$. En un siglo como el pasado, donde "la cantidad de maldad acumulada" solo puede explicarse desde una perspectiva esquizofisiológica, la alegoría se ha mostrado inútil en su pretensión de explicar el desenfreno histórico de lo humano. Documentos, descripciones de hechos, motivos sociológicos, etnológicos, psicológicos se mezclan en un corpus donde el escritor halla el medio creativo, para poder fijar esta realidad paranoica: "Indagar esta alocada combinación de circunstancias mediante la fuerza del documento, de la investigación, del procedimiento indagador, y sin intentar, por su propia cuenta y arbitrariamente, dar diagnósticos y proponer tratamientos y medicinas" $"$.

Si una obra como Una tumba fue substanciada por la crítica del establishment con el prejuicioso cliché de "simple variación del sempiterno tema del sufrimiento de los judíos" ${ }^{2}$, tildándola en consecuencia de periférica, particular, sospechosa o irrelevante, fue, pensamos, porque realmente tenía y tiene valor intrínseco y su moraleja había sido comprendida realmente. Su reto particular había sido bien comprendido y recogido. En palabras de Joseph Brodsky, todas las acusaciones formales contra la obra, "no fueron más que la punta de un enorme iceberg de odio real" 43 . En la Yugoslavia de 1976 toda postura ideológica estaba condicionada -nunca había dejado de estarlo- por el nacionalismo. Adentrarse en las catacumbas del estalinismo soviético para levantar acta de sus víctimas, informar en clave de ficción de la destrucción del Komintern y del exterminio, durante las purgas del año 1937, de sus miembros más cualificados, poco o nada tenía que ver con la Yugoslavia no alineada de Tito. $\mathrm{Y}$, sin embargo, la acusación de "plagiar", "modificar" o "releer" lanzada contra Kiš, ya fueran los supuestos clásicos de la historia oficial marxista, la novelística de algún autor soviético o la obra de James Joyce o Jorge Luis Borges expresaba en el acusador de turno, más bien en un fondo no demasiado profundo, algunos de los demonios que podían convertir a un simple escritor o a un poeta de otra nacionalidad del Estado en enemigo de todo y todos.

\subsection{El principio de asimetría hermenéutica}

Aquello que los censores de Danilo Kiš tan solo se atrevieron a barruntar, sin comprender del todo su alcance, fue la genial transformación que una breve obra como

Barcelona, El Aleph Editores, 2002.

39 D. Kiš, Lección de anatomía, op. cit., p. 64.

40 Carta a Strakhov: "Lo que la mayor parte de las gentes llaman fantástico y excepcional constituye de por sí la realidad más profunda", en H. Troyat, Dostoievski, Barcelona, Vergara, 2006, p. 351.

41 D. Kiš, Lección de anatomía, op. cit., p.65.

42 Ibidem, p. 17.

43 J. Brodsky, Prólogo a D. Kiš, Una tumba, op. cit., p. 11. 
Una tumba fue capaz de concebir, a partir de la historia contemporánea de Rusia. La maestría literaria Kiš se desplegó en una empresa singular de comprensión e iluminación: convertir la historia soviética en una nueva mitología de nuestra civilización, más allá de los clichés ideológicos al uso. A la inconmensurable catástrofe histórica y humana perpetrada en la Rusia soviética en la década de los años treinta y cuarenta, nunca se le concedió, durante la posguerra y la Guerra fría, el interés que hubiera sido considerado justo a tenor de la lectura que sí se hizo de los crímenes del nacionalsocialismo. Un principio de hermenéutica asimétrica se instaló entre Kolymá y Auschwitz, entre el Lager y el Gulag, un desfase del interés epistemológico que condenó a las víctimas del estalinismo a una segunda muerte, la del olvido.

Más allá de la simplificación de los fenómenos totalitarios, de la reducción simplista de manifestaciones políticas tan diferentes en su génesis, desarrollo y justificación como el bolchevismo y el nazismo a un constructo nivelador, indiscernible enemigo de la democracia occidental y su concepto de libertad, es necesaria la mención obligada de la diferencia. Un escritor e intelectual como Imre Kertész, deportado a Auschwitz a los quince años por su condición de judío húngaro, víctima posterior del kadarismo estalinista, se negaba rotundamente a aceptar la existencia de un único modelo de totalitarismo extrapolable a todas sus manifestaciones. En su momento, también expresaron esta negación con vehemencia personajes como Primo Levi o Jean Améry ${ }^{44}$. Frente a la tentación homogeneizadora o el énfasis en la singularidad de uno u otro fenómeno totalitario, se alza el imperativo ético del memento de las víctimas. Lo cierto, en cualquier caso, por más que un fenómeno no excluyera al otro, es que las víctimas del estalinismo fueron ocultadas tras las montañas de cadáveres de Buchenwald, tras las piras humanas de Sobibor y Treblinka, en la niebla caliginosa de Auschwitz ${ }^{45}$. Los millones de muertos de la Gran Guerra Patriótica las invisibilizaron aún más, quedando posteriormente abandonadas por el camino en medio de las disputas ideológicas de la Guerra Fría. Desaparecieron en silencio, casi definitivamente, como consecuencia de las complejas racionalizaciones que se operaban en gran parte de la intelligentsia occidental cada vez que salía a colación la cuestión de los abusos del socialismo real, racionalizaciones que conducían al desinterés y la indiferencia ${ }^{46}$. Tal vez, el error estribara en marcar la pauta comprensiva de dos fenómenos totalitarios diferentes como el nazismo y el estalinismo desde la perspectiva del énfasis superlativo. Tiene razón Tzvetan Todorov cuando afirma que está permitido no interesarse por los hit-parades del sufrimiento, por las jerarquías exactas en el martirologio, y sí por el carácter de ejemplaridad de todos los crímenes contra la humanidad. Frente a la singularidad superlativa que enjuicia moralmente al que perpetra cualquier comparación, ejemplaridad en el "suma y sigue", en pos del consenso social sobre la diferencia entre humanidad y barbarie, entre el bien y el mal ${ }^{47}$.

44 Cf. J. Améry, Más allá de la culpa y la expiación, Valencia, Pre-Textos, 2001, p. 95; I. Kertész, Un instante de silencio en el paredón, Barcelona, Herder, 1999, pp. 33-34; P. Levi, Si esto es un hombre (apéndice de 1976), Barcelona, Muchnik, 1995, pp. 196-199.

45 Frente a los defensores de la que podríamos denominar "singularidad exclusivista", George Steiner presenta una lectura teológica en clave negativa de "la fenomenología de los asesinatos masivos producidos en Europa, desde el sur de España hasta las fronteras del Asia Rusa entre 1936 y 1945". G. Steiner, En el Castillo de Barba Azul, Barcelona, Gedisa, 2001, p. 52

$46 \quad$ K. Schlögel, Terror y utopía, Barcelona, Acantilado, 2014, p. 13.

47 T. Todorov, Los abusos de la memoria, Barcelona, Paidós, 2000, pp. 39-43. 
El enorme valor de Una tumba para Boris Davidovich reside en la singular recuperación ética que su maestría literaria opera: la redención para el conocimiento y para la historia de las víctimas olvidadas. La sutil perspectivación de Kiš, su énfasis en la imaginación y el detalle, combinado con la distancia irónica, consigue que el sentimiento sea pensado ${ }^{48}$. Construida como un extenso poema dramático, la obra tiene la virtud de redefinir la tragedia como un medio que hace memoria de las víctimas "haciendo hablar al tiempo", equiparando el arte a la realidad humana. Del silencio tras las desapariciones y las purgas, del silencio del Gulag, surge la palabra, la comprensión estética allí donde el ethos enmudece. Aparentemente en sintonía con ellos, la poética de Kiš hace de su obra una empresa de comprensión cualitativamente distinta de la perspectiva interna representada por los clásicos que abordan la representación del universo concentracionario soviético. Hablamos, por ejemplo, del "intento de superación por el arte" iniciado por Solzhenitsyn en su Archipiélago Gulag (1973), o de la obra de Alexander Weissberg-Cybulski, Conspiracy of Silence (1952), relato personal a la vez que profundo análisis de las falsas autoinculpaciones durante la Gran Purga. También de la crónica del mundo concentracionario soviético Un mundo aparte (1951), del polaco Gustaw Herling-Grudzinki, del libro de historias cortas Relatos de Kolymá (1954-1973), de Varlam Shalamov o del testimonio de Karlo Štajner 7000 días en Siberia, con connotaciones muy personales para el autor $^{49}$.

Una tumba es una obra literaria en las antípodas filosóficas de la obra de Solzhenitsyn, no solo de Archipiélago Gulag, sino, más en concreto, de Un día en la vida de Iván Denisovich ${ }^{50}$. Se ha destacado el carácter de contra-modelo de una obra con respecto a la otra, perceptible ya desde la sospechosa similitud entre sus títulos y, sobre todo, al carácter antitético de la ficción kisheana con respecto al "camino del pathos" del autor ruso. Mientras que Una tumba nos habla de una experiencia única e incomparable que define la verdadera imagen del siglo XX, Solzhenitsyn hace de su relato, en el fondo, una variación más de los infinitos modos de presentación de la pasión cristiana. Kiš nos muestra cómo entre el hombre y la historia, cómplices por principio, se ha instalado durante el siglo XX una tensión jamás conocida antes. La historia, cuanto más hace padecer al hombre y más lo vapulea menos necesita de él, menos cuenta con él, mayor es el desamparo en el que lo sume ${ }^{51}$.

\subsection{Coda: la meditación sobre la historia}

Afirma E. L. Doctorow que antiguamente, cuando los únicos creadores eran Dios y sus profetas, se daba por hecho que las historias eran ciertas solo por el hecho de contar$\mathrm{se}^{52}$. En el contexto de la polémica literaria de aires dreyfusianos en la que se vio envuelto Kiš, y más en concreto en el asunto de "las fuentes" de Una Tumba, el relato de la "Los perros y los libros", adquirió una importancia decisiva. Para Dragan Jeremić,

$48 \quad$ J. Brodsky, op. cit., p. 12.

49 G. Herling-Grudzinki, Un mundo aparte, Barcelona, Libros del asteroide, 2012; A. Weissberg-Cybulski, Conspiracy of Silence, London, H. Hamilton, 1952; V. Shalamov, Relatos de Kolymá (5 vols.), Barcelona, Minúscula, 2009-2013; A. Solzhenitsyn, Archipiélago Gulag, Barcelona, Tusquets, 2014; K. Štajner, 7000 jours en Sibérie, Paris, Gallimard, 1983.

50 A. Solzhenitsyn, Un día en la vida de Iván Denisovich, Barcelona, Tusquets, 2008.

51 L. Proguidis, op. cit., p. 83.

52 E. L. Doctorow, Creadores, Barcelona, Roca, 2007, p.139. 
presidente de la Asociación Serbia de Escritores y gran urdidor de la trama, este relato representaba sin ambages "el ejemplo más impresionante de los préstamos que toma Kiš de textos ajenos", ya que no era más que "una copia casi integral de un documento judicial del siglo XIV"53. Todo ello cierto, como también cierto es que dicho relato culmina con una extensísima "nota del autor" donde se afirma lo siguiente:

La historia de Baruch David Neumann es, en realidad, una traducción del tercer capítulo del registro de la Inquisición, en el que Jacques Fournier, el futuro Papa Benedicto XII, apuntaba detallada y concienzudamente las confesiones y los testimonios ofrecidos ante el tribunal. El manuscrito se guarda en el Fondo Latino de la Biblioteca del Vaticano con el número $4030^{54}$.

No parecía, pues, una muy sagaz labor de investigador tal descubrimiento. El asunto era más bien otro. Respondía a una cuestión de sentido artístico, a la posibilidad o no de la inclusión de un documento medieval traducido en una obra literaria, a si es lícito y puede convertirse en literario un texto que no lo es. Boris Eichenbaum parece estar en lo cierto cuando afirma que el carácter específico del arte se expresa no en los elementos que entran en la obra, sino en la peculiar utilización que de ellos se hace ${ }^{55}$. Tan solo como el resultado de una ceguera provocada por primarios prejuicios ideológicos puede entenderse el que los críticos no fueran capaces de asumir algo tan evidente: que la crónica del proceso inquisitorial a un judío podía caber al lado de las crónicas de las víctimas de las purgas estalinistas. El descubrimiento de las desventuras de un judío obligado a la conversión forzosa y retornado a la fe de sus padres supuso para Kiš la experiencia de una inspiración, de un descubrimiento. Precursor en el tiempo del ministerio de desgracia de Boris Davidovich, la fuerza de sus convicciones, el parecido de sus nombres, el contexto de sus vidas, todo ello, se mostró ante la conciencia de Kiš y se muestra ante nosotros, lectores contemporáneos, "como una metáfora desarrollada de la clásica doctrina sobre el movimiento cíclico del tiempo" "56. Y aunque pueda alterarse la posición de partida del detonante que hace girar la rueda del tiempo, amplía la verdad que se cierne sobre esta historia

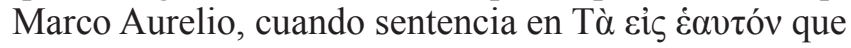

quien ha visto el presente, todo lo ha visto: a saber, cuántas cosas han surgido desde la eternidad y cuántas cosas permanecerán hasta el infinito. Pues todo tiene un mismo origen y un mismo aspecto ${ }^{57}$.

\section{Conclusión: el espejo invertido del mundo}

La disimilitud genuina de cada ser humano con respecto a los otros como fundamento de la dignidad de la existencia, la rabiosa individualidad como único fundamento

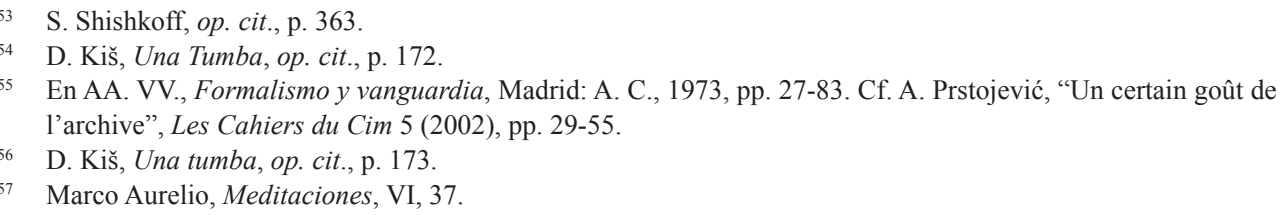


de la igualdad ética, es el principio filosófico-político que sostienen toda la narrativa de Kiš. Pudiendo encontrarse ya en la enumeración de los inquilinos del inmueble de La buhardilla, lo hallamos en el recuerdo pormenorizado de la destrucción de la comunidad judía de Novi Sad en Salmo 44 y El reloj de arena, así como en el recuento del universo de relaciones del protagonista del relato que da título a $L a$ Enciclopedia de los muertos. Como una suerte de faros estelares que permiten la orientación entre estas constelaciones, elementos recurrentes se erigen como hitos en el universo kisheano: evocaciones familiares, fechas, objetos y situaciones; referencias reales a libros, documentos, citaciones judiciales o médicas, hechos históricos; motivos geológicos, geográficos, cartográficos, metáforas de la configuración de la conciencia y de la existencia humana. Todos ellos enuncian una interpretación de la realidad asociada a una forma kantiana de conocimiento según la cual el mundo es cada una y todas sus representaciones individuales: "cada acontecimiento está ligado a su destino particular, todo está narrado a través de las propias visiones y en relación a la propia vida" 58 . En este sentido, enmarcadas por una cronología que es el eón de nuestra era, desde la Samaria de tiempos de Jesús hasta la Rusia estalinista, las historias de amor y de muerte de La enciclopedia conforman una suerte de lectura histórica de la levedad y la gravedad del ser. Con este fin, el autor despliega una prosa de enorme densidad y lirismo. Frente a la mistificación del logos, las obras de Danilo Kiš aspiran a ser un reto frente a la mediocridad del espíritu y la prestidigitación literaria ${ }^{59}$. Palabra e historia. En el retorno absoluto del pasado en el que insiste Kiš, sus textos son la sugerente manifestación de una profecía invertida. Una voz alzada frente a la historia que pasa de largo sin mirar el resultado de su devenir, frente a una historia presta, no obstante, a retornar revestida de su esencia eterna y enloquecida.

El pueblo teje incesantemente leyendas, los escritores despliegan su imaginación recreando vidas... "solo la muerte es innegable" 60 . La Biblioteca de "La Enciclopedia de los muertos (Toda una vida)" es un edificio que alberga tantas salas como letras del alfabeto inician las entradas de una enciclopedia. Allí se encuentra un enorme volumen, un enorme libro con el que "todo" se hace claro y "evidente". "Esotérica creación del espíritu humano", este libro en apariencia antiguo y sagrado, a diferencia del Sefer ha-Qabbalah, El Libro de la vida de los santos o El Libro tibetano de los muertos, tan sólo describe las relaciones, hechos, paisajes y detalles que conforman la vida de un único hombre. Al abrirse el libro, una montaña de recuerdos, fotografías, documentos y anotaciones de diario se ofrecen para su lectura. El libro es un espejo invertido. Antítesis del archivo familiar que acompañará a Danilo Kiš y que será fuente de inspiración para su poética, no es un conjunto de fragmentos a los que es necesario dar forma. Frente al desvelamiento doloroso de la existencia de Eduard Kiš, el padre desaparecido en Auschwitz, a partir de restos y fragmentos, de huellas débiles e inestables, La Enciclopedia se presenta como la síntesis objetiva, informativa e imparcial de una vida entera de un solo hombre. Merced a este carácter, la enciclopedia como forma de conocimiento representa "un verdadero tesauro en su necesidad de apuntarlo todo, todo lo que constituye una vida" 61 . Una paradoja se abre, pues, como una suerte de bucle infinito: el hombre, totalidad en sí, es frag-

\footnotetext{
D. Kiš, La Enciclopedia, op. cit., p. 60.

P. Matvejević, "Danilo Kiš: Encyclopedia of the Dead", Cross Currents 7 (1988), p. 347.

D. Kiš, La Enciclopedia, op. cit., p. 99.

Ibidem, p. 51.
} 
mento de un Todo que no es nada sin la concurrencia de sus partes. Lo singular y lo universal de la condición humana:

Porque nunca se repite nada en la historia de los seres humanos [...], todo lo que a primer avista aparece igual apenas es similar; cada hombre es un astro aparte, todo ocurre siempre y nunca, todo se repite hasta el infinito y de forma irrepetible ${ }^{62}$. 